\title{
Effects of stocking density on blood chemistry and amino enzymatic activity of juvenile Nile tilapia Oreochromis niloticus (Linnaeus, 1758) in hyperosmotic rearing condition
}

\author{
Jumah Yashier Upling 1,2,* \\ ${ }^{1}$ Aquaculture Department, College of Fisheries, Mindanao State University - Tawi-Tawi College of Technology and \\ Oceanography, Sanga-Sanga, Bongao 7500, Tawi-Tawi, Philippines. \\ 2 Institute of Aquaculture, College of Fisheries and Ocean Sciences, University of the Philippines Visayas, Miagao 5023, \\ Iloilo, Philippines.
}

Publication history: Received on 29 April 2020; revised on 06 May 2020; accepted on 07 May 2020

Article DOI: https://doi.org/10.30574/gscbps.2020.11.2.0120

\begin{abstract}
Nile tilapia Oreochromis niloticus, a euryhaline species, is a good candidate for culture in estuarine areas in the Philippine archipelago. Thus, the effects of stocking density on plasma cortisol, blood glucose, plasma aspartate transaminase (AST), and plasma alanine transaminase (ALT) were determined. The group of juvenile Nile tilapia $O$. niloticus $(14.67 \pm 0.12 \mathrm{~cm}$ TL and $44.57 \pm 0.48 \mathrm{~g} \mathrm{~W})$ was subjected to three different stocking densities $(6,12 \& 24 / 60$ L) for 14 days in $15 \%$ o rearing condition. The experiment was composed of three treatments with triplicated groups arranged in a completely randomized design (CRD). Highest stocking density affected the plasma cortisol, blood glucose, plasma AST and ALT of Nile tilapia by increasing its concentration level in the blood. These manifestations suggest that overcrowding in Nile tilapia affects the physiological function through hormonal secretion, glucose utilization, and protein catabolism of the species.
\end{abstract}

Keywords: Cortisol; Aspartate transaminase; Alanine transaminase; Plasma; Glucose.

\section{Introduction}

Nile tilapia Oreochromis niloticus L. is a euryhaline species that has considerable potential for culture in high saline waters, especially in the Philippines where estuarine environments are common. Adaptation of Nile tilapia in a hyperosmotic condition was previously reported [1]. The tilapia industry is growing rapidly since Nile tilapia $O$. niloticus became more accepted by the Filipinos [2]. Tilapia is now ranked second to milkfish as the most important cultured fish in the Philippines [3]. Given the limited space for freshwater aquaculture and pressures on providing the food demands of the growing population, tilapia is now being cultured in brackishwater ponds. The brackishwater tilapia farming will further intensify in the years to come to meet the cheap protein requirements of the increasing world human population. With the invasion of tilapia production into the brackishwater, an appropriate stocking density in these farming areas should be put into consideration. And as to optimize their culture condition, rearing density should be considered in fish culture intensification [4].

Rearing density is an important aspect for fish culture, and it has been demonstrated that rearing fish at inappropriate stocking densities may impair growth and reduce immune competence due to factors such as clustering stress and the deterioration of water quality, which can affect both the feed intake and conversion efficiency of the fish [5]. However,

\footnotetext{
* Corresponding author: Jumah Yashier Upling; Email: ajofflink@gmail.com; +63977 8166822
} 
it is not always clear whether the performance of fish is influenced by stress caused by suboptimal water quality parameters associated with high densities (e.g., low oxygen level, elevated ammonia, or carbon dioxide levels) or by aggressive behavior due to crowding [4].

Stress in farmed fish is of considerable significance to both welfare and productivity as it has been linked to a reduction in growth [6]. Particular attention has been paid to stocking density as one of the key factors to influence the perceived level of stress in fish [5]. Physiological alterations might be used as indicators for unsuitable environmental conditions or the presence of stressors encountered in intensive fish culture [4]. Stress in fish affects its overall performance as it undergoes several responses that compromise health and growth. It commences with an initial short-latency increase in plasma levels of catecholamines released from stores in the chromaffin tissue of the kidney, followed by a longer latency but usually more prolonged elevation in plasma cortisol levels following de novo synthesis by interrenal tissue [7]. Another study manifested that stress responses of this species include an increasing level of plasma cortisol [8]. The release of glucose is triggered by the effect of cortisol as fish maintaining its homeostatic state. As stress persisted, the stored protein was converted to glucose through deamination and transamination processes to further combat the stress. Depending on the persistence of stressors until fish become exhausted and eventually die. Amino enzymes catabolism as a coping mechanism in the hyperosmotic medium was previously observed in Nile tilapia [8].

Lowering the stocking density proved to improve the overall growth performance of tilapia species [9,10]. However, extensive farming is no longer practical nowadays as it requires huge production areas. And farming towards the sea in the hope of the future generation to attain food security. Thus, this study was conducted to determine appropriate stocking density in hyperosmotic conditions without compromising the overall health capability of the species. Specifically, the hematological indices such as plasma cortisol, blood glucose, plasma aspartate transaminase, and alanine transaminase of juvenile Nile tilapia reared in hyperosmotic conditions were quantified.

\section{Material and methods}

\subsection{Study site and duration}

The study was performed for 14 days (September 12, 2014 to September 26, 2014) at the Multi-Species Hatchery of the Institute of Aquaculture (IA), College of Fisheries and Ocean Sciences (CFOS), University of the Philippines Visayas (UPV), Miagao, Iloilo, Philippines.

\subsection{Animal source and acclimation}

Tilapia juveniles were obtained from the Freshwater Aquaculture Station (FAS), IA, CFOS, UPV, and immediately transported to the hatchery in oxygenated plastic bags via motorbike tricycle.

Organisms were acclimated in 2 tons capacity fiberglass rectangular tanks at a density of $10 \mathrm{~L}$ per individual for 15 days prior to experiment proper. Organisms were fed with floating commercial feeds (Tateh® Feeds) twice a day given in the early and middle afternoon at $1 \%$ average body weight (ABW) for body maintenance. Likewise, acclimation tanks were provided with aeration, and 5 to $10 \%$ water volume was replaced on a daily basis.

\subsection{Test organism and experimental design}

Nile tilapia (14.67 $\pm 0.12 \mathrm{~cm}$ TL and $44.57 \pm 0.48 \mathrm{~g} \mathrm{~W}$ ) stocked at 6,12 , and 24 individuals in $60 \mathrm{~L}$ tanks arranged in a completely randomized design (CRD). There were 3 treatments in triplicate groups with a total of 27 experimental units used in the experiment. Nine experimental tanks were taken out in each sampling period until the end.

\subsection{Experiment Proper}

The experimental tanks were supplied with continuous aeration and about $70 \%$ of water volume was changed twice every day. The wastes were siphoned using a small hose every day and tanks were cleaned using sponge every other day. Experimental organisms were fed twice daily at 3\% average body weight (ABW) with Tateh@ tilapia starter surfer feeds. 


\subsection{Stocking and monitoring}

The experimental tanks having low (6/60 L), moderate (12/60 L), and high (24/60 L) stocking densities were subjected to a rearing exposure of $15 \%$ o salinity level. Adjustment of salinity was done by diluting seawater with tap freshwater to achieve the desired concentration of salinity. The water salinity was measured by a refractometer (ATAGO HHR-2N). Other water quality parameters such as temperature, dissolved oxygen, $\mathrm{pH}$, and total ammonia were monitored using DO meter (YSI model 55-12 FT), pH meter (HI 99104), and total ammonia test kit (Advance Pharma Co., LTD) in situ.

\subsection{Blood sampling in fish}

A sampling of the fish blood was done thrice throughout the experiment, which carried out within 24 hrs after stocking, 7 days, and end of the culture period.

Feeding was stopped 24 hours before sampling. Before blood extraction, organisms were anesthetized using 2phenoxyethanol at $1 \mathrm{ml} \mathrm{L}^{-1}$ concentration as described by Morgan et al., [11]. In every sampling, 1 to $1.5 \mathrm{ml}$ of blood was taken from each fish through caudal vein puncture using a heparinized needle and $1 \mathrm{ml}$ syringe. Blood samples were immediately placed in a styrofoam box with ice after extraction. Collected blood was centrifuged at $3000 \mathrm{rpm}$ for 10 minutes to collect blood plasma using a refrigerated centrifuge (HETTICH 4903-02-0). The upper colorless fluid in the microcentrifuge tube was collected and transferred to another tube. Plasma samples were stored at $-80{ }^{\circ} \mathrm{Cin}$ the ultralow freezer (ILSHIN NKH10579) until analyzed.

\subsection{Sample analysis}

Quantitative analysis of fish cortisol (ng/ml) was done using an enzyme-linked immunosorbent assay (ELISA) kit (SunLong Biotech Co., LTD). Enzymatic readings were determined using the microtiter plate reader (Ledetect 96 ELISA). Blood glucose (ml/dL) was quantified following the method of Mustafa et al., [12] in which ooze of fresh blood from the severed caudal peduncle was slightly dropped into the tip of the glucose strip that was inserted in a standard glucometer (Apex Biotechnology Corp.) and reading of the result was obtained in situ. Plasma aspartate transaminase (AST) (ng/ml) and alanine transaminase (ALT) (pg/ml) content were analyzed using enzyme-linked immunosorbent assay (ELISA) kit (SunLong Biotech Co., LTD) following the company standard manual.

\subsection{Data Analyses}

Data on plasma cortisol, plasma aspartate transaminase (AST), plasma alanine transaminase (ALT) were analyzed using Statistical Package for the Social Sciences (SPSS) version 20 in one-way ANOVA (Analysis of Variance). Duncan Multiple Range Test (DMRT) was used as a post hoc analysis to determine the significant difference among treatments. The level of significance was set at $\alpha=0.05$ and 0.01 in all data. Data presented in tables are expressed in means \pm SEM in triplicate groups.

\section{Results and discussion}

Within 24 hours of the experiment, results showed no significant difference $(p>0.05)$ in blood glucose. However, analysis of variance (ANOVA) showed a highly significant difference in plasma cortisol $(p<0.01)$, and significantly increased at higher stocking density (Table 1).

Table 1 Blood glucose and plasma cortisol level of Nile tilapia O. niloticus after 24 hrs. of rearing period in $60 \mathrm{~L}$ tank.

\begin{tabular}{lll}
\hline \multicolumn{3}{c}{ Biological Indices } \\
\hline Stocking Density & Cortisol $(\mathrm{ng} / \mathrm{ml})$ & Glucose $(\mathrm{mg} / \mathrm{dL})$ \\
6 & $67.97 \pm 0.86 \mathrm{~b}$ & $175.44 \pm 21.00 \mathrm{a}$ \\
12 & $64.89 \pm 0.40 \mathrm{~b}$ & $143.26 \pm 21.37 \mathrm{a}$ \\
24 & $76.70 \pm 0.69 \mathrm{a}$ & $197.06 \pm 38.21 \mathrm{a}$ \\
ANOVA (P value) & 0.001 & 0.196 \\
\hline \multicolumn{2}{c}{ Means \pm SE having the same letter are not significant $(p>0.05)}$.
\end{tabular}


Increasing plasma cortisol level was observed in response to high stocking density within $24 \mathrm{hrs}$ of the culture period. Initially, the highest cortisol level was found within a high stocking density group, suggesting that high stocking density resulted in stress manifestation, which rapidly increased blood cortisol levels. The plasma cortisol means of 76.70 \pm 0.69 $\mathrm{ng} / \mathrm{ml}$ found in higher stocking density conditions were higher than the $40 \mathrm{ng} / \mathrm{ml}$ characteristic of stress Nile tilapia previously reported [13]. Even though Barreto and Volpato [14] reported that the cortisol baseline for 0 . niloticus ranges from $\sim 5$ to $60 \mathrm{ng} / \mathrm{ml}$ and thus contradict Barcellos et al., [13], the cortisol level in this study suggests that fish underwent stress during rearing condition. An abrupt increase in plasma cortisol level within 24 hours of exposure might suggest an acute stress response caused by overcrowding in this species. Acute stress causes a rapid increase in plasma cortisol in other teleost species which has been reviewed [15]. And the recovery from stress in terms of the return of plasma cortisol to resting levels may be slowed if stressor still exists in the recovery environment [7].

On the $7^{\text {th }}$ day of rearing, results showed no significant difference in plasma cortisol $(p>0.05)$. On the contrary, blood glucose and plasma ALT were highly significant $(p<0.01)$. Likewise, plasma AST was also significantly affected by the stocking density (Table 2).

Table 2 Plasma cortisol, blood glucose, plasma AST and ALT level of Nile tilapia O. niloticus after 7 days of rearing in $60 \mathrm{~L}$ tank.

\begin{tabular}{lllll}
\hline \multicolumn{5}{l}{ Biological Indices } \\
\hline Stocking Density & Cortisol $(\mathrm{ng} / \mathrm{ml})$ & Glucose $(\mathrm{mg} / \mathrm{dL})$ & AST $(\mathrm{ng} / \mathrm{ml})$ & ALT $(\mathrm{pg} / \mathrm{ml})$ \\
6 & $90.39 \pm 5.24 \mathrm{a}$ & $114.94 \pm 2.42 \mathrm{~b}$ & $5.01 \pm 0.16 \mathrm{~b}$ & $1248.83 \pm 14.54 \mathrm{~b}$ \\
12 & $82.80 \pm 4.99 \mathrm{a}$ & $214.33 \pm 10.81 \mathrm{a}$ & $5.34 \pm 0.26 \mathrm{ab}$ & $1313.90 \pm 2.10 \mathrm{a}$ \\
24 & $84.83 \pm 6.71 \mathrm{a}$ & $194.50 \pm 10.49 \mathrm{a}$ & $5.65 \pm 0.35 \mathrm{a}$ & $1334.89 \pm 7.57 \mathrm{a}$ \\
ANOVA (P value) & 0.159 & 0.005 & 0.019 & 0.000 \\
\hline \multicolumn{5}{r}{ Means \pm SE having the same letter are not significant $(p>0.05)}$.
\end{tabular}

In this study, cortisol level did not go down into a resting level but instead even went up after 7 days of the culture period. This means that reared species at different stocking densities underwent physiological stress. The lack of significant differences $(p>0.05)$ observed among high, moderate, and low stocking densities might not only be due to overcrowding effect or water quality deterioration but rather it was influenced by behavioral activities including biting and chasing which were more pronounced in a lower density. A similar observation was also reported by Barcellos et al., [13] in Nile tilapia that social stress may result in the occurrence of a chronic stress response which is probably caused by antagonistic encounters among the members of the group. This scenario persisted until day 14 of the rearing period, where high cortisol level was shown by 0 . niloticus raised at a lower density. This suggests that the hierarchy in 6 individuals per $60 \mathrm{~L}$ is still pronounced.

A significant increase in blood glucose towards higher stocking densities was found after a week of culture. Normally, the increase of glucose in plasma is not as rapid as for cortisol and it has been reviewed that an increase of glucose occurs hours or even days after the stress has manifested [15]. Glucose elevations are primarily generated by cortisolmediated gluconeogenesis [7]. According to Barreto and Volpato [14] the blood glucose from 45 to $130 \mathrm{mg} / \mathrm{dL}$ is the non-stressed baseline characteristic of the Nile tilapia. A review by Pankhurst [7] elucidated that post-stress responses usually lead to increased plasma glucose. The effects of higher stocking density on the increase in blood glucose have been reported in other species [16,17]. Glucose is responsible for the provision of energy that is used by fish to cope with stress $[18,19,20,21,4]$. The rise of glucose during this time might be due to the density-dependent factors mainly attributed to social stress brought about by the aggressive encounters and dominant/submissive relationships that are common in this species [21].

By the end of the study, all biological indices were significantly affected by stocking density. However, plasma cortisol level was higher in low stocking density while higher blood glucose concentrations were observed at higher stocking density. Likewise, similar trends were also manifested in plasma AST and ALT (Table 3). 
Table 3 Plasma cortisol, blood glucose, plasma AST and ALT level of Nile tilapia O. niloticus after 14 days of rearing in $60 \mathrm{~L}$ tank.

\begin{tabular}{lllll}
\hline \multicolumn{5}{l}{ Biological Indices } \\
\hline Stocking Density & Cortisol (ng/ml) & Glucose $(\mathrm{mg} / \mathrm{dL})$ & AST $(\mathrm{ng} / \mathrm{ml})$ & ALT $(\mathrm{pg} / \mathrm{ml})$ \\
6 & $162.72 \pm 3.93 \mathrm{a}$ & $134.12 \pm 23.24 \mathrm{ab}$ & $4.10 \pm 0.06 \mathrm{~b}$ & $1292.91 \pm 3.64 \mathrm{~b}$ \\
12 & $114.50 \pm 8.88 \mathrm{~b}$ & $114.83 \pm 13.41 \mathrm{~b}$ & $4.41 \pm 0.19 \mathrm{a}$ & $1229.94 \pm 3.64 \mathrm{bc}$ \\
24 & $139.50 \pm 11.28 \mathrm{a}$ & $200.34 \pm 19.27 \mathrm{a}$ & $4.91 \pm 0.28 \mathrm{a}$ & $1437.75 \pm 20.09 \mathrm{a}$ \\
ANOVA ( P value) & 0.003 & 0.022 & 0.014 & 0.002 \\
\hline \multicolumn{5}{l}{ Means \pm SE having the same letter are not significant $(p>0.05)}$.
\end{tabular}

The plasma aspartate transaminase (AST) was significantly elevated at high stocking density at the end of the study. The degree of response was caused by the influence of stocking density as a stress factor which suggests that increased stocking density caused stress to the experimental organisms. The previous finding stated that aspartate is one of the major glucogenic precursors and important energy substrate for fish thus increasing activities of plasma AST indicated amplified transamination processes [22]. Besides, aspartate is essential to purine nucleotide synthesis in all cell types. Aminotransferases are intracellular enzymes that are normally localized within the cells of the liver, heart, gills, kidney, muscle, and other organs. The levels of these enzymes increase in the plasma when the cells are damaged or their membranes disrupted, allowing the enzymes to leak out of the cells [23]. Higher stocking density caused higher plasma AST as the stress response was also reported previously in Nile tilapia 0 . niloticus and they also concluded that stocking density of tilapia up to 6 fish $\mathrm{m}^{-3}$ showed an adverse effect on the liver functions [24].

Similarly, other work reported that 3 fish $\mathrm{m}^{-3}$ obtained the lowest value of AST in silver carp, Hypophthalmichthys molitrix fingerlings suggesting that fish were essentially normal and within the range consistent with good fish health [17]. Previous study mentioned that stress elevates the internal oxidizing effort towards membrane permeability that increases the fluxes of AST enzymes into the bloodstream [25]. Kamal and Omar [17] reported on silver carp H. molitrix that plasma AST increased at higher stocking density. This parameter is known as a sensitive indicator of even minor cellular damage in the liver of fish.

Effect of stocking density as stressor caused higher plasma alanine transaminase (ALT) at the end of the culture period. Aside from aspartate, alanine is also a major glucogenic precursor and important energy substrates for fish. Moreover, alanine is a preferred carrier of nitrogen for inter-organ amino acid metabolism [22], as several amino acids can be converted to alanine, released to the blood, and used as a fuel source in other tissues in fish [26].

Ovie and colleague [23] also suggested that aminotransferases play vital roles in carbohydrate-protein metabolism in fish and other organisms' tissues. The aminotransferases occupy a central position in the amino acid metabolism as they help in retaining amino groups (to form new amino acid) during the degradation of amino acid and are also involved in the biochemical regulation of intracellular amino acid pools. They help in providing necessary intermediates for gluconeogenesis. The observed alterations in their activities in the exposed fish may, therefore, have an adverse effect on the amino acid metabolism of the tissues and consequently the intermediates required for gluconeogenesis [23]. The levels of these enzymes increase in the plasma when the cells are damaged or their membranes disrupted, allowing the enzymes to leak out of the cells. These enzymes are therefore of major importance in assessing and monitoring liver cytolysis [23]. Thus, the present experiment implies that higher stocking density may cause organ damage. Plasma enzyme levels depend on the rate of release of enzymes from damaged cells, which in turn depends on the rate at which damage is occurring and at the extent of cell damages [23]. This result indicates the consistent stress effect of increasing the stocking density on liver functions of the fish as reported by Kamal and Omar [17] on silver carp H. molitrix. This result further indicates fish liver tissue destruction. ALT concentrations would increase because of its role in an initial amino acid compensation and formation that the body needs in physiological changes that require increased energy demands. Further, this also suggests that the increase in plasma ALT was due to infiltration of the enzymes to the bloodstream [25]. This was in line with the work of Melotti et al., [27] in rainbow trout brought by a high density of the 
intensive rearing conditions. This plasma ALT increment might be due to the increase in liver protein destruction and energy demand [25].

This result corroborates that of Aly et al., [24] who reported in Nile tilapia that ALT levels were significantly increased by increasing stocking density. This was attributed to the stress response that has been associated with increased amino acid levels as a consequence of activated catabolism and inhibited protein synthesis. On the other hand, the elevation in the ALT was attributed to the damage of hepatic cells and other tissues and escaping of this enzyme to the blood [24].

The experiment was done indoor and utilized small containers to single out factors affecting the physiological aspect of Nile tilapia in the brackishwater farm. However, it was revealed that social aggressiveness was also triggered by small confinement in this species. Thus, species in the farm site might show different characteristic behavior compared to the result of the study. With this regard, a future study on the stocking density of Nile tilapia should consider several factors such as; uniformity of size, sex, water flow, and shading.

\section{Conclusion}

Findings of the present study suggest that stocking density affects the physiological function of Nile tilapia $O$. niloticus by increasing the cortisol level, blood glucose, and levels of amino acid catabolizing enzymes that include ALT and AST. These results add to the present knowledge on the physiological responses and coping mechanisms of Nile tilapia reared in an overcrowding hyperosmotic environment.

\section{Compliance with ethical standards}

\section{Acknowledgments}

The author acknowledges the Office of the Vice-Chancellor for Research and Extension-University of the Philippines Visayas (OVCRE-UPV), Department of Science and Technology-Accelerated Science and Technology Human Resource Development Program (DOST-ASTHRDP) for funding this research output. Special thanks to my M.Sc. thesis adviser Dr. Rex Ferdinand M. Traifalgar.

\section{Disclosure of conflict of interest}

Author declares no possible conflict of interest from any individual, party or entity.

\section{Statement of ethical approval}

The experiment was performed based on the ethical approved guidelines set by the UPV on the humane act of handling and dissecting the specimen during sampling.

\section{References}

[1] Jumah, YU, Traifalgar RFM, Monteclaro HM, Sanares RC, Jumah DU and Mero FC. (2016). Influence of hyperosmotic culture conditions on osmoregulatory ions, gill chloride cells and $\mathrm{Na}+\mathrm{K}+$-ATPase activity of Nile tilapia, (Oreochromis niloticus). AACL Bioflux, 9(3), 498-506.

[2] Smith IR, Torres EB and Tan EO. (1985). Philippine tilapia economics. ICLARM Conference Proceedings 12, 261. Philippine Council for Agriculture and Resources Research and Development, Los Baños, Laguna and International Center for Living Aquatic Resources Management, Manila, Philippines.

[3] PSA (Philippine Statistic Authority) (2019). Fisheries statistics of the Philippines 2016 - 2018. Philippine Statistic Authority, East Avenue, Diliman Quezon City, Philippines, 27, 279.

[4] Abdel-Tawwab M, Mousa MA, Sharaf SM and Ahmad MH. (2005). Effect of crowding stress on some physiological functions of Nile tilapia (Oreochromis niloticus) fed different dietary protein levels. International Journal of Zoological Research, 1(1), 41-47. 
[5] Ellis T, North B, Scott AP, Bromage NR, Porter M and Gadd D. (2002). The relationships between stocking density and welfare in farmed rainbow trout. Journal of Fish Biology, 61, 493-531.

[6] Wedemeyer GA. (1996). Physiology of fish in intensive culture systems. Chapman and Hall, ITP, New York, 232.

[7] Pankhurst NW. (2011). The endocrinology of stress in fish: an environmental perspective. A review. General Comparative and Endocrinology, 170(2), 265-275.

[8] Jumah YU and Traifalgar RFM. (2015). Stress response and amino enzymes catabolism of Nile tilapia (Oreochromis niloticus) exposed to hyperosmotic culture conditions. Asian Journal of Animal Sciences, 9(6), 379387.

[9] Dawood MAO, Metwally AE, El-Sharawy ME, Atta AM, Elbialy ZI, Abdel-Latif HMR and Paray BA. (2020). The role of $\beta$-glucan in the growth, intestinal morphometry, and immune-related gene and heat shock protein expressions of Nile tilapia (Oreochromis niloticus) under different stocking densities. Aquaculture, 523, 735205.

[10] Chikorela G, Chirwa ER and Mzengereza K. (2019). Optimal stocking density of Tilapia rendalli (Boulenger, 1896) for increased growth in a periphyton based aquaculture system. Journal of Fisheries and Aquatic Sciences, 14, 33-38.

[11] Morgan JD, Sakamoto T, Grau EG and Iwama GK. (1997). Physiological and respiratory responses of the Mozambique tilapia (Oreochromis mossambicus) to salinity acclimation. Comparative Biochemistry and Physiology, A 117(3), 391-398.

[12] Mustafa AS, Hayat A and Quarrar P. (2013). Stress modulated physiological responses in Nile tilapia (Oreochromis niloticus) treated with non-ascorbic acid supplemented feed. Advanced Zoology and Botany, 1(2), 39-45.

[13] Barcellos LJG, Nicolaiewsky S, De Souza SMG and Lulhier F. (1999). The effect of stocking density and social interaction on acute stress response in Nile tilapia (Oreochromis niloticus) L. fingerlings. Aquaculture Research, 30, 887-892.

[14] Barreto RE and Volpato GL. (2006). Stress responses of the fish Nile tilapia subjected to electroshock and social stressors. Brazilian Journal of Medical and Biological Research, 39, 1605-1612.

[15] Martinez-Porchas M, Martinez-Cordova LF and Romeo-Enriques R. (2009). Cortisol and glucose: reliable indicator of fish stress? A review. Journal of Aquatic Science, 4(2), 158-178.

[16] Braun N, Lima RL, Baldisserotto B, Dafre AL and Nuñer AP. (2013). Biochemical changes in Salminus brasiliensis due to successive captures and stocking densities. Acta Scientiarum: Biological Sciences, 35(1), 9-13.

[17] Kamal SM and Omar WA. (2011). Effect of different stocking densities on hematological and biochemical parameters of silver carp (Hypophthalmichthys molitrix) fingerlings. Journal of Life Science, 8(4).

[18] Aketch BO, Ang'ienda PO, Radull JO and Waindi EN. (2014). Effect of stocking density on the expression of glucose transporter protein 1 and other physiological factors in the Lake Victoria Nile tilapia (Oreochromis niloticus L.). International Aquatic Research, 6, 69.

[19] Kpundeh MD, Xu P, Yang H, Qiang J and He J. (2013). Stocking densities and chronic zero culture water exchange stress' effects on biological performances, hematological and serum biochemical indices of GIFT tilapia juveniles (Oreochromis niloticus). Journal of Aquatic Research and Development, 4, 189.

[20] EL-Khaldi AT. (2010). Effect of different stress factors on some physiological parameters of Nile tilapia (Oreochromis niloticus). Saudi Journal of Biological Sciences, 17, 241-246.

[21] Evans JJ, Pasnik DJ, Horley P, Kraeer K and Klesius PH. (2008). Aggression and mortality among Nile tilapia (Oreochromis niloticus) maintained in the laboratory at different densities. Research Journal of Animal Sciences, 2(2), 57-64.

[22] Li P, Mai K. Trushenski J and Wu G. (2008). New developments in fish amino acids nutrition: towards functional and environmentally oriented aquafeeds. Amino Acids, 37, 43-53.

[23] Ovie KS, Bemigho IR and Gbemi OM. (2010). Variations in alanine aminotransferase and aspartate Aminotransferase activities in African catfish (Clarias gariepinus) (Burchell, 1822) at different sublethal concentrations of potassium permanganate. Scientific Research and Essays, 5(12), 1501-1505. 
[24] Aly SM, Taha RM and El-Bhar SM. (2009). The effect of stocking density on some biochemical parameters of Oreochromis niloticus. Faculty of Veterinary Medicine, Suez Canal University, 1, 101-110.

[25] Al-Khashali MS and Al-Shawi SAS. (2013). Effect of salt stress on ALT and AST enzymes activity and cortisol level in adults of Carassius auratus. Pakistan Journal of Nutrition, 12 (1), 97-100.

[26] Tseng YC and Hwang PP. (2008). Some insights into energy metabolism for osmoregulation in fish. Comparative Biochemistry and Physiology, 148(3), 419-429.

[27] Melotti P, Roncarati A, Angellotti L, Dees A, Magi GE, Mazzini C, Bianchi C and Casciano R. (2004). Effects of rearing density on rainbow trout welfare, determined by plasmatic and tissue parameters. Italy Journal of Animal Science, 3, 393-400.

\section{How to cite this article}

Jumah YU. (2020). Effects of stocking density on blood chemistry and amino enzymatic activity of juvenile Nile tilapia Oreochromis niloticus (Linnaeus, 1758) in hyperosmotic rearing condition. GSC Biological and Pharmaceutical Sciences, 11(2), 36-43. 